\title{
TroyAcademy
}

International Journal of Social Sciences

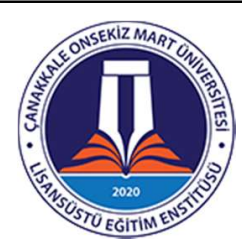

\section{Pazarlamaya İlişkin Kararlarda Farklı Departmanların Etkisi ${ }^{1}$}

\author{
Araştırma Makalesi/Research Article
}

\section{Güngör HACIOĞLU* Osman GÖK**}

\section{ÖZET}

$\mathrm{Bu}$ çalışmanın amacı, firmadaki beş temel departmanın (pazarlama, satış, Ar-Ge, üretim ve finans), pazarlamaya ilişkin kararlar üzerinde ne derece etkisi olduğunu araştırmaktır. $\mathrm{Bu}$ doğrultuda, her bir departmanın bu kararlar üzerindeki etki düzeyleri belirlenerek, departmanlar arası karşılaştırma yapılmakta ve her bir departmanın etkisinin firma performansı ile ilişkisi araştırılmaktadır. Bunun yanı sıra, kararlardaki etkinin departmanlar arasında dağılımının firma performansı üzerindeki etkisi araştırılmaktadır. Bu amaca yönelik olarak, Türkiye'de faaliyet gösteren 220 üretim firmasından, yapılandırılmış anket aracılığıyla toplanan veriler analiz edilmiştir. Analiz sonucunda, firmadaki pazarlamaya ilişkin kararlar üzerinde pazarlama ve satış departmanlarının oldukça etkili olduğu görülmektedir. Pazarlamanın, en çok etkili olduğu kararlar reklam ve en az etkili olduğu kararlar da ürün geliştirme kararlarıdır. Pazarlama ve satış departmanlarının kararlar üzerinde etkisi arttıkça firma performansının düştüğü, diğer departmanlarının etkisinin performans üzerinde bir etkiye sahip olmadığı bulgusuna ulaşılmıştır. Kararlar üzerindeki etkinin departmanlar arasında dağılımı ile performans arasında da bir ilişkiye rastlanmamıştır. Çalışmanın sonunda uygulamacılar ve gelecek çalışmalar için önerilere yer verilmektedir.

Anahtar Kelimeler: Pazarlama Departmanı, Pazarlama Kararlarl, Pazarlamanın Rolü, Firma Performansı

\section{Decision Influences of Major Departments on Marketing Related Issues}

\begin{abstract}
Responding to calls for research in the area, this study empirically examines the decision influence of five major departments -marketing, sales, R\&D, manufacturing and finance- on marketing related issues. The amounts of influence exercised by each department are portrayed and compared, and their relations with firm performance are explored. Besides, the dispersion of influence and performance are discovered. To the end, the data collected from a sample of 220 Turkish manufacturing firms via a structured questionnaire derived from the literature are analyzed. Results reveal that marketing and sales departments are the most influential ones within the firm. The amount of influence exercised by marketing and sales are negatively related with firm performance, while others have no relationship with firm performance. Dispersion of influence among departments has no effect on firm performance. Managerial implications and future research issues are discussed.
\end{abstract}

* Dr. Öğr. Üyesi, Çanakkale Onsekiz Mart Üniversitesi, Biga İktisadi ve İdari Bilimler Fakültesi, İşletme Bölümü, gungor.hacioglu@gmail.com, ORCID ID: https://orcid.org/0000-0003-0694-9607

${ }^{* *}$ Prof. Dr., Yaşar Üniversitesi, İşletme Fakültesi, osman.gok@yasar.edu.tr, ORCID ID: https://orcid.org/00000002-4859-9855 
Keywords: Marketing Department, Marketing Decisions, Role of Marketing, Firm Performance

\section{GíRİş}

Pazarlamanın firma içindeki rolü ve etkisi, hem araştırmacıların hem de uygulamacıların ilgisini çeken bir konu olmaya devam etmektedir. Pazarlamanın önemini yitirdiği, daha az ilgi çektiği ve güçsüz hale geldiği söylenmektedir (McGovern vd., 2004). Pazarlama faaliyetlerine verilen önemin azaldığı ve pazarlamanın departman olarak da gücünün düşüşte olduğu ifade edilmektedir (Day, 1992; Webster, Malter ve Ganesan, 2005). Araştırmacılar, firma içinde pazarlama fonksiyonunun küçüldüğünü (Greyser, 1997), pazarlama faaliyetleri için dış kaynak kullanımının arttığını (Kumar, 2004; McGovern ve Quelch, 2005; Ueltschy vd., 2006) ve pazarlamaya ait rollerin örgüt içinde dağıldığını öne sürmektedirler (Krohmer, Homburg ve Workman, 2002; Webster, Malter ve Ganesan, 2005; Harris ve Ogbonna, 2003). Birçok stratejik kararın ve hatta geleneksel olarak pazarlamanın üstlendiği bazı işlerin bile, artık pazarlamanın görevi olmaktan çıktığı ve diğer departmanlar tarafından üstlenilmeye başlandığg ortaya konulmaktadır ((Nath ve Mahajan, 2008; Srivastava, Shervani ve Fahey, 1999; Sheth ve Sisodia, 2005). Pazarlama departmanlarının görev ve sorumlulukları, neredeyse sadece tutundurma ile ilişkili faaliyetleri yönetmekten ibaret olacak şekilde daralmaktadır (Gök ve Hacioglu, 2010). Bu tartışmalar üzerine, pazarlamanın firma içindeki rolünü ve kararlardaki etkilerini araştıran daha çok gelişmiş ülkelerde bazı çalışmalar yapılmıştır (örn., Homburg vd., 1999; Moorman ve Rust, 1999; Verhoef ve Leeflang, 2009; Merlo ve Auh, 2009; Oswald vd., 2012; Merlo, Lukas ve Whitwell, 2012; Wirtz, Tuzovic ve Kuppelwieser, 2014; Hattula vd., 2015; Krush vd., 2015). Pazarlamanın firma içindeki varlığı ve rolüne ilişkin daha çok ABD, Almanya, Hollanda gibi gelişmiş ülkelerde çalışma yapıldığı ve bu konuda daha fazla çalışma yapılmasına ihtiyaç olduğu da açıktır (Merlo ve Auh, 2010). Özellikle de gelişmekte olan ülkelerde yapılmış çalışmaların (örn., Engelen ve Brettel, 2012) az olmasından dolayı bu ülkelerde çalışma yapılması önem taşımaktadır (Burgess ve Steenkamp, 2006). Çünkü, pazarlamanın etkisinin toplumsal tutum, ekonomik gelişmişlik ve yasal düzenlemelerle ilişkili olabileceği düşünülmektedir (Homburg vd., 1999). Bu bağlamda bu çalışmanın amac1, Türkiye'de faaliyet gösteren üretim firmalarında pazarlamaya ilişkin kararlarda pazarlama ve diğer departmanların etkisini araştırarak bu boşluğu doldurmaktır. Bu konuda literatürdeki açığı kapatmak bağlamında bu çalışmanın üç katkısı olacağı düşünülmektedir. İlk olarak, pazarlamaya ilişkin kararlar üzerinde temel departmanların etkilerinin belirlenmesi amaçlanmaktadır. İkinci olarak, her bir departmanın bu kararlardaki etki düzeylerinin firmanın genel performansı üzerindeki etkisi araştırılacaktır. Son olarak da pazarlama kararları üzerindeki etkinin departmanlar arasında dağılımının performans üzerinde etkisi olup olmadığı belirlenmeye çalışılacaktır. Çalışmanın bundan sonraki bölümünde, kavramsal çerçeve 
ortaya konulmakta ve yapılan çalışmalar ele alınmaktadır. Sonrasında, araştırmanın yöntemi açıklanarak bulgular sunulmaktadır. Çalışmanın sonunda, sonuçlar tartışılmakta, uygulamacılar ve gelecek çalışmalar için öneriler sunulmaktadır.

\section{KAVRAMSAL ÇERÇEVE}

Etki, kişilerin kendi öneri, tavsiye veya emirlerinin takip edilmesi için diğer kişileri ikna etmeyi başarma sürecidir (Merlo vd., 2012). Pazarlama departmanının etkisi, departmanın firma içinde önemli olarak görülmesi ve diğer departmanlara göre güç sahibi olması olarak tanımlanabilir (Verhoef vd., 2011). Homburg vd.'ye (1999) göre güç, her bir alt birimin örgütteki diğer üyelerin tutum ve davranışlarında değişim yaratabilme yeterliliği, etki ise bu gücün başarılı bir şekilde hayata geçirilmesidir. Homburg vd. (1999), pazarlamanın etkisini ise, "işletme için önemli olan faaliyetler üzerinde pazarlama departmanının diğer departmanlara göre sahip olduğu gücün kullanımı” olarak tanımlamaktadır. Merlo (2011) pazarlamanın ayrı bir departman olarak etkisini, stratejilerin geliştirilmesi ve uygulanmasında departmanın tavsiyeleriyle diğerlerini ikna etmesi olarak ele almaktadır. Örgütsel tasarımda temel konulardan birisi de pazarlama faaliyetleri üzerinde örgüt içinde kimlerin daha fazla etki sahibi olması gerektiğidir (Krohmer et al. 2002). 1990'l1 yıllardan itibaren pazarlamanın departman olarak önemini kaybettiği ve onun yerine pazar odaklılık kavramının önem kazanmaya başladığı görülmektedir (Webster vd., 2005). Pazar odaklılık kültürünün firmalarda yerleşmesiyle pazarlamanın sadece bir departmanın görevi olmaktan çıtı̆ğ ve firmadaki tüm departmanların ve çalışanların görevi haline geldiği öne sürülmektedir (Shipley, 1994). Oswald vd. (2012) temel departmanların pazar odaklılık üzerindeki etkisini araştırdığ çalışmasında, pazarlama ve satış departmanlarının hem tepkisel hem de proaktif pazar odaklılık üzerinde olumlu etkisi olduğu sonucuna ulaşmıştır. Moorman ve Rust (1999) ise, pazar odaklılığın etkisinin, güçlü bir pazarlama departmanının varlığına bağlı olduğunu ve pazarlama departmanının firma performansına doğrudan olumlu etkisinin de olduğunu ortaya koymaktadır. Benzer şekilde, Merlo ve Auh (2009), pazar odaklılığın performans üzerinde doğrudan bir etkisinin olmadığını ancak güçlü bir pazarlama departmanına sahip olunmasının firma başarısına katkı sağladığını bulmuştur. Verhoef vd. (2011) tarafından yapılan ve yedi ülkeyi kapsayan çalışmada, yedi ülkeden beşinde pazarlama departmanının etkisinin pazar odaklılı̆̆ı arttırmanın ötesinde firma performansını da doğrudan etkilediği görülmektedir. Homburg vd. (1999) etkili bir pazarlama departmanının daha iyi performans için gerekli olduğu sonucuna ulaşmıştır. Ancak, Verhoef ve Leeflang (2009) ile Hattula vd. (2015), pazarlamanın finansal performans üzerinde doğrudan etkisi olmamakla birlikte, pazar odaklılığın bu ilişkiye aracılık ettiği bulgusuna ulaşmıştır. Pazarlama departmanının firma içinde etkisine ilişkin çalışmalar dışında, ayrıca firmanın stratejik kararları ve pazarlama kararları 
üzerindeki etkinin departmanlar arasında dağılımının etkileri de yapılan çalışmalarla incelenmiştir. Krohmer vd. (2002), pazarlama faaliyetleri üzerindeki etkinin departmanlar arasındaki dağılımının firma performansı üzerinde olumlu bir etkisinin olduğu sonucuna ulaşmıştır. Engelen (2011) firmanın stratejik kararları üzerindeki etkinin departmanlar arasında dağılımı ile performans arasında ters-U şeklinde bir ilişki olduğunu bulmuştur. Krush vd. (2015) de pazarlama yeterliliklerinin firma içindeki dağılımının pazarlama departmanının etkisini azalttığını ancak performans üzerinde doğrudan olumlu etkisi olduğunu bulmuştur.

\section{ARAŞTIRMANIN YÖNTEMI}

Çalışmada öne sürülen hipotezleri test etmek için Türkiye'de faaliyet gösteren üretim firmalarından veri toplanmıştır. Çalışmanın örneklemini İstanbul Sanayi Odası (ISO) tarafından açıklanan Türkiye'nin en büyük 500 sanayi şirketi oluşturmaktadır. Bu şirketlerde görev alan yaklaşık 1400 yönetici ve bu şirketlere ait yaklaşık 600 genel e-posta adresi bir araştırma firması aracılığıyla elde edilmiştir. Elde edilen e-posta adreslerine Internet yoluyla anketler gönderilmiş ve toplam 225 adet geri dönüş sağlanmıştır. Alıcıya ulaşmayan 132 adet anket çıkarıldığında geri dönüş oranı yaklaşık $\% 12$ olarak belirlenmiştir. Bu tür araştırmalarda \%12 ile \%20 arasında bir geri dönüş oranının uygun olduğu (Churchill, 1991) düşünüldüğünde bu oranın yeterli olduğu söylenebilir. Eksik doldurulan 5 adet anket çıkarıldıktan sonra 220 adet analize uygun ankete ulaşılmıştır. Örnekleme dahil olan katılımcıların \%56,8'i nihai tüketici ve \%43,2'si endüstriyel tüketiciye yönelik ürünler üreten firmalarda yer almaktadır. Katılımcıların firmaları, otomotiv, makine, tekstil, gıda gibi birçok farklı alanda faaliyet göstermektedir. Katılımcıların \%15,5'inin firmalarının üst yönetiminde yer aldığ 1 görülmektedir. Katılımcıların, 17,7'sinin pazarlama, \%18,6'sının satış, \%16,8'inin finans/muhasebe, \%13,2'sinin üretim, \%5,5'inin satın alma, \%4,5'inin Ar-Ge ve \%5,9'unun diğer bölümlerden olduğu görülmektedir. Bundan dolayı, örneklemin çeşitli endüstrilerden farklı müşteri profillerine sahip firmalardan ve bu firmaların farklı bölümlerinden katılımcılar içerdiğini ve dengeli bir örneklem yapısına ulaşıldığını söylemek mümkündür. Olası yanıtlanmama hatasını belirlemek için, erken ve geç yanıt verenlerin cevapları arasında t-testi yapılmış (Armstrong ve Overton, 1977) ve böyle bir durumun söz konusu olmadığı görülmüştür $(\mathrm{p}>$.05). Firma performansını ölçmek için, çeşitli çalışmalar (Moorman ve Rust, 1999; Verhoef ve Leeflang, 2009) temel alınarak oluşturulan ve performansın pazar ve karlılığa ilişkin bazı ölçütlerini içeren sübjektif performans ölçeği kullanılmıştır. Her bir departmanın kararlardaki etkisini ölçmek için Homburg vd. (1999) tarafından oluşturulan ve sonrasında diğer araştırmacılar tarafından da benzer şekilde kullanılan ölçüm modeli kullanılmıştır. Buna göre, katılımcılara reklam, müşteri sadakat programları, müşteri memnuniyeti ölçümü ve geliştirilmesi, hedef pazarların ve müşterilerin seçimi, müşteri hizmetleri, dağıtım, 
fiyatlama ve yeni ürün geliştirme kararları üzerinde beş farklı departmanın (pazarlama, satış, finans, üretim ve Ar-Ge) ne derece etkili olduğu sorulmuştur. Katılımcılardan 100 puanı ilgili departmanlar arasında, daha etkili olan departman daha çok puan alacak şekilde dağıtmaları istenmiştir. Kararlardaki etkinin departmanlar arasında dağılımını belirlemek için, her bir karardaki puanların standart sapmaları hesaplanmıştır (Krohmer vd., 2002). Departmanlar arasında kararlardaki etki puanları arasındaki fark arttıkça standart sapma da artacak, kararlardaki etkinin departmanlar arasında dağılımı arttıkça standart sapma düşecektir. Verilerin analizinde ilk olarak departmanların pazarlama kararları üzerindeki etki puanlarına ilişkin tanımlayıcı istatistikler ortaya konulmaktadır. Ayrıca, her bir departmanın etkisi ile firma performansı arasındaki ilişkiyi belirlemek üzere regresyon analizleri yapılmaktadır. Son olarak da kararlardaki etkinin departmanlar arasında dağılımı ve firma performansı arasındaki ilişki için regresyon analizi yapılmaktadır.

\section{VERILERIN ANALIZİ VE BULGULAR}

Farklı departmanların söz konusu pazarlama kararları üzerindeki etki seviyeleri belirlenmiş ve kararlar pazarlama departmanının etki seviyesine göre sıralanmıştır (Tablo 1). Buna göre, pazarlama departmanının en etkili olduğu karar alanının reklam (\%54) olduğu görülmektedir. Pazarlama departmanının daha çok etkili olduğu diğer alanlar müşteri sadakat programları $(\% 46)$, müşteri memnuniyeti (\%41), hedef pazar ve müşteri seçimi $(\% 40)$ ile müşteri hizmetleri $(\% 36)$ olarak sıralanmaktadır. Pazarlamanın reklam dışında müşteriye ilişkin kararlar konusunda diğer tüm departmanlardan daha etkili olduğu görülmektedir. Söz konusu kararlar konusunda satış departmanının ikinci sırada yer aldığı ve önemli ölçüde etkiye sahip olduğu görülmektedir. Aynı zamanda pazarlama departmanının etkisi azaldıkça satış departmanının etkisi artmaktadır. Dağıtım ile ilgili kararlarda satış departmanının pazarlama departmanından daha fazla etki sahibi olduğu ve pazarlama departmanının önüne geçtiği bulunmuştur. Fiyatlama kararlarına ilişkin olarak da satış departmanı pazarlamadan daha etkilidir. Fiyatlama kararları, finans departmanının en etkili olduğu karar alanıdır ve bu konuda göreceli olarak yüksek etkiye sahiptir. Yeni ürün geliştirme kararları konusunda en etkili departman, Ar-Ge departmanıdır. Bunun diğer kararlar ile karşılaştırıldığında hem pazarlamanın hem de satışın en az etkili oldukları karar konusu olduğu görülmektedir. Üretim departmanı ise diğer kararlara göre bu konuda kısmen daha etkindir.

Tablo 1. Temel Departmanların Pazarlama Kararları Üzerindeki Etkileri

\begin{tabular}{|l|c|c|c|c|c|c|}
\hline & Pazarlama & Satış & Finans & Üretim & Ar-Ge & Diğer \\
\hline Pazarlama Kararları & & & & & & \\
\hline Reklam & 54 & 25 & 5 & 2 & 4 & 10 \\
\hline Sadakat programları & 46 & 31 & 4 & 4 & 5 & 10 \\
\hline
\end{tabular}




\begin{tabular}{|l|c|c|c|c|c|c|}
\hline Müşteri memnuniyeti & 41 & 29 & 3 & 7 & 7 & 13 \\
\hline Hedef pazar ve müşteri & 40 & 39 & 4 & 3 & 5 & 9 \\
\hline Müşteri hizmetleri & 36 & 34 & 4 & 8 & 7 & 11 \\
\hline Dağıtım & 31 & 42 & 6 & 5 & 2 & 14 \\
\hline Fiyatlama & 28 & 36 & 14 & 9 & 8 & 5 \\
\hline Ürün geliştirme & 28 & 23 & 3 & 10 & 29 & 7 \\
\hline
\end{tabular}

Her bir departmanın tüm kararlar üzerindeki etkilerinin ortalamaları alınarak, departmanların pazarlama kararları üzerindeki etki seviyeleri belirlenmiştir. Tablo 2.'de görüldügü üzere pazarlama departmanı en etkili departmandır. Pazarlamanın ardından satış departmanının pazarlama kararları üzerinde en etkili ikinci departman olduğu görülmektedir. Bu iki departmanın birlikte pazarlama kararları üzerinde önemli bir etkiye sahip oldukları ve diğer departmanların etkisinin görece olarak çok az olduğu görülmektedir. Departmanların etki seviyelerinin kendi aralarındaki korelasyonlara bakıldığında, pazarlamanın etkisi diğer tüm departmanlarla ters orantılıdır ve pazarlamanın etkisi arttıkça diğerlerinin etkisini düşmektedir. Özellikle de pazarlama ve satış arasında yüksek oranda negatif bir korelasyon $(r=-0,62)$ söz konusudur. Benzer şekilde satış ile finans arasında da ters yönlü bir ilişki $(r=-0,22)$ olduğu görülmektedir. Üretim departmanı etkisi ile satış ve finans arasında anlamlı bir ilişki yoktur ancak Ar-Ge ile pozitif yönlü ve anlamlı bir ilişkisi $(r=0,20)$ mevcuttur.

Tablo 2. Tanımlayıcı İstatistikler ve Korelasyonlar

\begin{tabular}{|l|l|c|c|c|c|c|c|c|}
\hline & Departmanlar & Ortalama & S.S. & $\mathbf{1}$ & $\mathbf{2}$ & $\mathbf{3}$ & $\mathbf{4}$ & $\mathbf{5}$ \\
\hline 1. & Pazarlama & 37,95 & 23,67 & 1 & & & & \\
\hline 2. & Sat1ş & 31,68 & 21,61 & $-0,62^{* *}$ & 1 & & & \\
\hline 3. & Finans & 5,33 & 9,47 & $-0,15^{*}$ & $-0,22^{* *}$ & 1 & & \\
\hline 4. & Üretim & 6,22 & 6,94 & $-0,32^{* *}$ & $-0,01$ & 0,11 & 1 & \\
\hline 5. & Ar-Ge & 8,85 & 9,67 & $-0,18^{* *}$ & $-0,13$ & $-0,01$ & $0,20^{* *}$ & 1 \\
\hline 6. & Firma Performans1 & 5,39 & 0,96 & $-0,137$ & $-0,04$ & $-0,03$ & 0,11 & 0,13 \\
\hline
\end{tabular}

$* \mathrm{p}<0,05 * * \mathrm{p}<0,01$

Firmadaki temel departmanlar ile firma performansı arasındaki ilişkiyi ortaya çıkarabilmek amacıyla doğrusal regresyon analizi yapılmıştır (Tablo 3). Yapılan analiz sonucunda departmanların pazarlama kararları üzerindeki etki seviyelerinin firma performansındaki varyansın \%3,8'ini açıklayabildiği ve modelin istatistikî olarak anlamlı olduğu sonucuna ulaşılmaktadır. Bağımsız değişken olarak modele dâhil edilen pazarlama ve satış departmanlarının etkisi ile performans arasında negatif yönlü ve anlamlı bir ilişki vardır (sırasıyla, $\beta=-0,293$ ve $\beta=-0,244$ ), ancak diğer departmanların etkisi ile performans arasında anlamlı bir ilişki yoktur. 
Tablo 3. Departmanların Etkisi ile Performans İlişkisine Dair Regresyon Analizi

\begin{tabular}{|l|c|c|c|}
\hline Departmanlar & $\boldsymbol{\beta}$ & $\mathbf{t}$ & $\mathbf{p}$ \\
\hline Pazarlama & $-0,293$ & $-2,633$ & 0,009 \\
\hline Satış & $-0,244$ & $-2,317$ & 0,022 \\
\hline Finans & $-0,128$ & $-1,630$ & 0,105 \\
\hline Üretim & 0,018 & 0,237 & 0,813 \\
\hline Ar-Ge & 0,045 & 0,593 & 0,554 \\
\hline \multicolumn{4}{|l|}{$\mathrm{F}=2,573$} \\
\hline
\end{tabular}

Bağımlı değişken: Firma Performansı

Son olarak, pazarlama kararları üzerinde departmanların etkisinin dağılımı ile firma performansı arasında ilişki olup olmadığını belirlemek amacıyla regresyon analizi yapılmıştır (Tablo 4). Bu amaca yönelik olarak her bir karar unsuru için, departmanların etki puanlarının standart sapmaları hesaplanmış ve hesaplanan sekiz standart sapmanın ortalaması alınmıştır. Kararlardaki etkinin dağılımının bağımsız değişken olarak alındığı regresyon modelinin anlamlı olmadığı görülmüştür $(\mathrm{R} 2=0,004 ; \mathrm{p}=0,739)$. Kararlardaki etkinin departmanlar arasında dağılımının performans üzerinde herhangi bir açıklama gücü olmadığı sonucuna ulaşılmıştır.

Tablo 4. Kararlardaki Etkinin Dağılımı ile Performans İlişkisine Dair Regresyon Analizi

\begin{tabular}{|l|c|c|c|}
\hline Departmanlar & $\boldsymbol{\beta}$ & $\mathbf{t}$ & $\mathbf{p}$ \\
\hline Kararlardaki Etkinin Dağ1lımı & 0,024 & 0,333 & 0.739 \\
\hline \multicolumn{2}{|c|}{$\mathrm{F}=0,111 \quad$ Düz. $\mathrm{R}^{2}=0,004$} & $\mathrm{p}=0,739$ \\
\hline
\end{tabular}

Bağımlı değişken: Firma Performansı

\section{SONUÇ VE ÖNERILER}

Literatürde pazarlama departmanının firma içindeki önemi ve alınan kararlar üzerindeki etkinliği tartışılmaktadır. $\mathrm{Bu}$ çalışmalarda pazarlamanın önemi ve kararlardaki etkisinin sebepleri ve sonuçlarına bakılmakta ve pazar odaklılık, girişimcilik odaklılık gibi bazı diğer değişkenlerle ilişkisi araştırılmaktadır. Bu bağlamda yapılan çalışmalarda temel çıkış noktası, pazarlamanın öneminin ve kararlardaki etkisinin azalmasıdır. Geleneksel olarak pazarlamaya atfedilen işlerin diğer departmanlar tarafından üstlenilmeye başlandığı ve pazarlamaya ilişkin kararlarda pazarlamanın sahip olması gereken etkinin örgüt içinde dağılmasıdır. Ancak pazarlama kararlarında diğer departmanların etkisinin arttı̆̆ı söylenmekle birlikte, bu etkinin diğer departmanlara ne şekilde dağıldığı ve bu dağılımın sonuçları üzerine çok fazla çalışma yapılmamıştır. Bundan dolayı bu çalışmanın literatürdeki bu boşluğu doldurması açısından önemli bir katkısı olacağı düşünülmektedir. Çalışmada pazarlama kararları üzerinde departmanların etkisi ortaya konulmaktadır ve departmanların sahip olduğu etki seviyelerinin ve etkinin dağılımının performans üzerindeki etkisi 
araştırılmaktadır. Analizler sonucunda pazarlama ve satış departmanlarının oldukça önemli bir etkiye sahip olduğu görülmüştür. Ancak departmanların etkisinin performans ile ilişkisine bakıldığında hem pazarlamanın hem de satışın negatif ilişkili olduğu görülmektedir. Engelen (2011) de maliyet liderliği stratejisi izleyen firmalarda pazarlamanın etkisinin performans ile negatif ilişkili olduğunu göstermiştir. Türkiye'de faaliyet gösteren firmalar örnekleminde de ilişkinin negatif olmasının sebebinin, Türk firmalarının da maliyet odaklı strateji izliyor olmalarından kaynaklanmış olabileceği düşünülebilir. Pazarlama yatırımları genellikle orta ve uzun vadeli sonuçlar ürettiğinden ve önemli harcama gerektirdiğinden, maliyet odaklı firmalarda performans üzerinde baskılayıcı bir etkisi olduğu algısı oluşabilir. Homburg vd. (1999), elde ettikleri bulguların ABD'de yapılan çalışmalardan farklı olmasını, ABD ile Almanya arasında pazarlama olgusunun adaptasyonu açısından farklar olmasına bağlamaktadır ve bu farkın daha az gelişmiş ülkelerde daha fazla olacağını öne sürmektedir. Türkiye gibi gelişmekte olan ülkeler ile ABD ve diğer batı ülkeleri arasında pazarlama olgusunun adaptasyonu, pazarlama faaliyetlerinin kısıtlı oluşu, pazarlama ve dağıtım faaliyetlerini destekleyecek altyapının gelişmemiş olması ve pazarlamaya karşı toplumsal tutumlar gibi farkların olmasının (Homburg vd., 1999), pazarlamanın firma başarısındaki rolünü olumsuz etkilediği düşünülebilir. Pazarlamaya karşı toplumsal tutum, ekonomik gelişmişlik ve yasal düzenlemeler açısından farklı ülkelerde yapılacak çalışmalarla daha genellenebilir sonuçlara ulaşmak mümkün olabilecektir. Pazarlamaya süreç odaklı yaklaşım ile iddia edilen, pazarlamanın tüm örgüte yayılan genel bir yönetim fonksiyonu haline geldiği savının henüz Türkiye'deki üretim firmalarında doğrulanmadığı görülmektedir. Pazarlama ve satış kararlarının örgüt geneline yayılmadığı, hala büyük oranda pazarlama ve satış departmanlarının tekelinde olduğu gözlenmektedir. Ancak pazarlamacıların verdikleri kararlarda etkinlik, verimlilik gibi konulara yeterince önem vermemesinin, alınan kararların firmanın etkinliğine olumlu katkı sağlamasını engellediği, hatta firma performansını olumsuz etkilemesine sebep olduğu söylenebilir. Bundan dolayı, pazarlama uygulamacılarının aldıkları kararlarda ölçülebilirliği göz önünde tutmaları ve yatırımın geri dönüşüne daha fazla önem vermeleri gerekmektedir. Pazarlama departmanının kararlar üzerindeki etkisi arttıkça diğer tüm departmanların etkisinin azaldığı görülmektedir. Pazarlamanın departmanlar arası işbirliğine daha fazla önem vermesinin ve kararlar üzerinde diğer departmanların da katkı sağlamasının kararların etkinliğini arttırabileceği düşünülebilir. Ayrıca departmanlar arası çatışmaların sebepleri ve sonuçları üzerine yapılacak çalışmalar da işbirliğini engelleyen unsurların belirlenmesini ve çözüm yollarının bulunmasını sağlayabilir. Çalışmada performans, katılımcıların sübjektif görüşleri doğrultusunda ve kesitsel olarak belirlenmiştir. Pazarlama yatırımlarının ve harcamalarının olumlu etkilerinin uzun vadede ortaya çıktığı düşünüldüğünde, boylamsal çalışmalar 
yapılmasıyla pazarlamanın firma performansı üzerindeki etkilerinin daha iyi anlaşılabileceği düşünülmektedir.

\section{KAYNAKÇA}

Armstrong, J.S. ve Overton,T.S. (1977). "Estimating Nonresponse Bias in Mail Surveys". Journal of Marketing Research, 14: 396-402.

Burgess, S.M. ve Steenkamp, J.-B.E.M. (2006). "Marketing Renaissance: How Research in Emerging Markets Advances Marketing Science and Practice", International Journal of Research in Marketing, 23(4), 337-56.

Churchill, G.A. ve Jr. (1991). Marketing research: Methodological foundations. 5th ed. Chicago, IL: The Dryden Press.

Day, G.S. (1992), "Marketing's Contribution to the Strategy Dialogue," Journal of the Academy of Marketing Science, 20 (4), 323-29.

Engelen, A. (2011). "Which Department Should Have More Influence on OrganizationLevel Decisions? A Strategy-dependent Analysis", Journal of Strategic Marketing, 19, 229-254.

Engelen, A. ve Brettel, M. (2012). "A Coalitional Perspective on the Role of The R\&D Department within the Organization", Journal of Product Innovation Management, 29, 488-504.

Gök, O. ve Hacioglu, G. (2010). "The Organisational Roles of Marketing and Marketing Managers", Marketing Intelligence and Planning, 28(3), 291-309.

Greyser, S.A. (1997). "Janus and Marketing: the Past, Present, Prospective Future of Marketing", in Lehmann, D.R. and Jocz, K. (Eds), Reflections on the Futures of Marketing, Marketing Science Institute, Cambridge, MA, pp. 3-14.

Harris, L.C. ve Ogbonna, E. (2003). "The Organization of Marketing: A Study of Decentralized, Devolved and Dispersed Marketing Activity", Journal of Management Studies, 40(2), 483-512.

Hattula, J. D., Schmitz , C., Schmidt, M. ve Reinecke, S. (2015). "Is More Always Better? An Investigation into The Relationship Between Marketing Influence and Managers' Market Intelligence Dissemination”, International Journal of Research in Marketing, In Press.

Homburg, C., Workman, J.P., ve Krohmer, H. (1999). "Marketing's Influence within the Firm", Journal of Marketing, 63(2), 1-17.

Krohmer, H., Homburg, C. ve Workman, J.P. (2002). "Should Marketing Be CrossFunctional? Conceptual Development and International Empirical Evidence", Journal of Business Research, 55(6), 451-65.

Krush, M.T., R. Sohi, S. ve Saini, A. (2015). "Dispersion of Marketing Capabilities: Impact on Marketing's Influence and Business Unit Outcomes", Journal of the Academy of Marketing Science, 43, 32-51.

Kumar, N. (2004). Marketing As Strategy: Understanding The CEO's Agenda For Driving Growth And Innovation. Boston: Harvard Business School Press.

McGovern, G.J., Court, D., Quelch, J.A. ve Crawford, B. (2004). "Bringing Customers Back into the Boardroom," Harvard Business Review, 82(11), 70-80.

McGovern, G. ve Quelch, J. (2005). "Outsourcing Marketing”, Harvard Business Review, 83(3), 22-3. 
Merlo, O. ve Auh, S. (2009). "The Effects of Entrepreneurial Orientation, Market Orientation, and Marketing Subunit Influence on Firm Performance". Marketing Letters, 20(3): 295-311.

Merlo, O. ve Auh, S. (2010). "Marketing's Strategic Influence in Australian Firms: A Review and Survey", Australasian Marketing Journal, 18(2), 49-56.

Merlo, O. (2011). "The Influence of Marketing from a Power Perspective". European Journal of Marketing, 45(7/8), 1152-1171.

Merlo, O., Lukas, B.A. ve Whitwell, G.J. (2012). "Marketing's Reputation and Influence in The Firm," Journal of Business Research, 65(3), 446-452.

Moorman, C. ve Rust, R.T. (1999). "The Role of Marketing”, Journal of Marketing, 63(Special Issue), 180-197.

Nath, P. ve Mahajan, V. (2008). "Chief Marketing Officers: A Study of Their Presence in Firms' Top Management Teams", Journal of Marketing, 72(1), 65-81.

Oswald, M., Brettel, M. ve Engelen, A. (2012). "How Departments' Decision-Making Influence and Interdepartmental Dynamics Relate to Two Facets of Strategic Market Orientation", Journal of Strategic Marketing, 20(6), 483-507.

Sheth, J.N. ve Sisodia, R.S. (2005). "Does Marketing Need Reform?", Journal of Marketing, 69 (4), 10-12.

Shipley, D. (1994). "Achieving cross-functional co-ordination for marketing implementation", Management Decision, 32(8), 17-20.

Srivastava, R.K., Shervani, T. A. ve Fahey, L. (1999). "Marketing, Business Processes and Shareholder Value: An Organizationally Embedded View of Marketing Activities and the Discipline of Marketing", Journal of Marketing, 63(4), 168179.

Ueltschy, L.C., Ryans, J.K. Jr. ve Herremans, I. (2006). "Marketing: Who’s Really Minding the Store Globally?", Business Horizons, 49(2), 139-148.

Verhoef, P.C. ve Leeflang, P.S.H. (2009). "Understanding the Marketing Department's Influence within the Firm," Journal of Marketing, 73(2), 14-37.

Verhoef, P.C., Leeflang, P.S.H., Reiner, J., Natter, M., Baker, W., Grinstein, A.,Gustafsson, A., Morrison, P. ve Saunders, J. (2011).“A Cross-National Investigation into the Marketing Department's Influence within the Firm: Towards Initial Empirical Generalizations", Journal of International Marketing, 19 (3), 59-86.

Webster, F.E., Malter, A.J. ve Ganesan, S. (2005), "The Decline and Dispersion of Marketing Competence,” MIT Sloan Management Review, 46 (Summer), 35-43.

Wirtz , J., Tuzovic , S. ve Kuppelwieser , V.G. (2014). "The role of marketing in today's enterprises", Journal of Service Management, 25(2), 171 - 194.

\section{Decision Influences of Major Departments on Marketing Related Issues EXTENDED SUMMARY}

The role and impact of marketing within the firm remains a topic of interest to researchers and practitioners alike. It is said that marketing loses its importance, attracts less attention and becomes weak (McGovern et al., 2004). It is stated that the importance given to marketing activities has decreased and the power of marketing as a department is decreasing (Day, 1992; Webster, Malter, \& Ganesan, 2005). Researchers argue that the marketing function within the firm has shrunk (Greyser, 1997), outsourcing for marketing activities has increased (Kumar, 2004; McGovern \& Quelch, 2005; Ueltschy et al., 2006), and marketing roles have been dispersed within the organization (Krohmer, 
Homburg). and Workman, 2002; Webster, Malter, and Ganesan, 2005; Harris and Ogbonna, 2003). It has been revealed that many strategic decisions, and even some tasks traditionally undertaken by marketing, are no longer the task of marketing and are started to be undertaken by other departments ((Nath \& Mahajan, 2008; Srivastava, Shervani \& Fahey, 1999; Sheth \& Sisodia, 2005).

The duties and responsibilities of the marketing departments are narrowing down to almost only managing the activities related to promotion (Gök and Hacioglu, 2010). Based on these discussions, some studies have been carried out mostly in developed countries, investigating the role of marketing in the firm and its effects on decisions (eg, Homburg et al., 1999; Moorman and Rust, 1999; Verhoef and Leeflang, 2009; Merlo and Auh, 2009; Oswald et al., 2012; Merlo, Lukas, \& Whitwell, 2012; Wirtz, Tuzovic, \& Kuppelwieser, 2014; Hattula et al., 2015; Krush et al., 2015).

However, it is clear that more studies have been conducted in developed countries such as the USA, Germany, and the Netherlands on the presence and role of marketing within the firm, and more studies are needed on this subject (Merlo and Auh, 2010). Especially since studies conducted in developing countries (eg, Engelen \& Brettel, 2012) are few, it is important to conduct studies in these countries (Burgess \& Steenkamp, 2006). In this context, the aim of this study is to fill this gap by investigating the effects of marketing and other departments on decisions regarding marketing in manufacturing companies operating in Turkey. It is thought that this study will make three contributions in the context of closing the gap in the literature on this subject. First, it is aimed to determine the effects of the main departments on the marketing decisions. Second, the impact of each department's level of influence on these decisions on the overall performance of the firm will be explored. Finally, it will be tried to determine whether the distribution of the impact on marketing decisions among departments has an impact on performance. In the next part of the study, the conceptual framework of the study is presented and the studies are discussed. Afterwards, the method of the research is explained and the findings are presented. At the end of the study, the results are discussed and suggestions for practitioners and future work are presented.

The impact of the marketing department can be defined as the department being seen as important within the company and having power over other departments (Verhoef et al., 2011). According to Homburg et al. (1999), power is the ability of each sub-unit to create change in the attitudes and behaviors of other members of the organization, and effect is the successful realization of this power. Homburg et al. (1999) defines the impact of marketing as "the use of the power of the marketing department over other departments over activities that are important to the business".

Merlo (2011) considers the impact of marketing as a separate department as the department persuades others with its recommendations in the development and implementation of strategies. One of the main issues in organizational design is who should have more influence on marketing activities within the organization (Krohmer et al. 2002). It is seen that since the 1990s, marketing has lost its importance as a department and the concept of market orientation has started to gain importance instead (Webster et al., 2005).

It is argued that with the establishment of a market-oriented culture in companies, marketing ceases to be the duty of only one department and becomes the duty of all departments and employees in the company (Shipley, 1994). (2012) found that the marketing and sales departments had a positive effect on both reactive and proactive market orientation. Moorman and Rust (1999) reveal that the effect of market orientation depends on the existence of a strong marketing department and that the marketing department has a direct positive effect on firm performance. 
Similarly, Merlo and Auh (2009) found that market orientation does not have a direct effect on performance, but it contributes to firm success if having a strong marketing department. Verhoef et al. (2011) in a study covering seven countries, it is seen that the influence of the marketing department in five of the seven countries directly affects the performance of the firm beyond increasing market orientation. Homburg et al. (1999) concluded that an effective marketing department is essential for better performance. However, Verhoef and Leeflang (2009) and Hattula et al. (2015) found that although marketing does not have a direct effect on financial performance, market orientation mediates this relationship. Apart from the studies on the impact of the marketing department within the company, the strategic decisions of the company and the effects of the distribution of the impact on the marketing decisions among the departments have also been examined.

Krohmer et al. (2002) concluded that the distribution of the impact on marketing activities among departments has a positive effect on firm performance. Engelen (2011) found that there is an inverted-U-shaped relationship between the distribution of the impact on the firm's strategic decisions among departments and performance. Krush et al. (2015) also found that the distribution of marketing competencies within the firm reduces the influence of the marketing department, but has a direct positive effect on performance.

Responding to calls for research in the area, this study empirically examines the decision influence of five major departments -marketing, sales, $R \& D$, manufacturing and finance- on marketing related issues. The amounts of influence exercised by each department are portrayed and compared, and their relations with firm performance are explored. Besides, the dispersion of influence and performance are discovered. To the end, the data collected from a sample of 220 Turkish manufacturing firms via a structured questionnaire derived from the literature are analyzed. Results reveal that marketing and sales departments are the most influential ones within the firm. The amount of influence exercised by marketing and sales are negatively related with firm performance, while others have no relationship with firm performance. Dispersion of influence among departments has no effect on firm performance. Managerial implications and future research issues are discussed. 